\title{
Entrepreneurship and Juju (Black Magic)
}

\author{
Jelena Zivkovic \\ American University of Nigeria
}

\begin{abstract}
All over the present Africa witch-finders, sorcerers seem to appear from nowhere, flourish for a period of time and disappear and then again reappear. Either it is some individual of extra ordinary personality in his/her community who pronounces a magic remedy or preventive for human needs and sufferings and thereby develops a following or else it is an organized band of wonder-workers. The incidence of Juju as a black magic is widespread in Sub-Saharan Africa especially in Nigeria. In spite of modernization and the rising call for education, the incidence of black magic in these areas remains unaltered. Like everything else, Juju has a good aspect and a bad aspect. Good Juju is used to bring good luck and fortune whereas bad juju is done with the intention of harming or hurting others. The people of Nigeria do not refrain from using such occult traditions to solve their problems as well as serve their ulterior motifs. The incidence and application of Juju is evident in different spheres and dimensions of the Nigerian society and culture, regardless of their income and education. The study follows a mixed approach of study and deploys both close ended and open ended questionnaire to collect both quantitative and qualitative data respectively in the form of surveys, interviews and focus groups to understand the rationale of the businessmen of Nigeria using juju for their safety and prosperity.
\end{abstract}

Keywords: Black magic, entrepreneurship, juju, Nigeria

\section{Introduction}

There are multitudinous manifestations of West African spiritual beliefs and religion. If we were to consider the disposition of the religions and their practices across the world in percentage terms, one can see that Christianity accounts for $33 \%$ of the world share in terms of the practicing religion, which is followed by Islam, which is practiced by $21 \%$ of the world population. $6 \%$ of the world population practices or believe in traditional African faiths which is equal to the number of people following Buddhism or Chines traditional beliefs and is quite large than the people following Judaism (0.22) or Sikhism (0.36) across the world.

\section{Background}

For many years, juju has occupied an integral role in Nigerian culture, and its cultural significance also stems from the fact that it is prevalent throughout the broader landscape of the Sub-Saharan African region. Along with Christianity, Islam, and economic and cultural "modernity," juju remains one of the fundamental aspects of human experience within Nigerian culture. Juju is derived from the French word joujou which means a toy or a plaything. Juju comes from the traditional African religion known as voodoo and it is a part of African culture. The notions regarding are not unidirectional as some believe that voodoo is effectuated to help people whereas juju is carried out to harm the people. Voodoo practitioners are mostly herbalists and wise men who use herbs and barks of tress to cure diseases. Juju performers on the other hand use objects like skull of dead animals, human skulls to perform juju rituals. While some others believe that juju is a diplomatic power derived out of medicinal and ritual art exploration. Juju in due course of time has attained spiritual value. Juju has the good and the bad aspect of magic and can be used for internal, spiritual and physical healing and contrary to this, bad juju invokes revenge, jealousy, causes bad or ill luck.

\section{Problems Of The People And Juju}

Juju is, holding the traditional belief in spirit and phantom world and how god affects the everyday activities of life. It is this form of witchcraft that has canonically surfaced prevalently within Nigerian culture. In the present moment, such fetishes are small in size and intentionally shaped, with the belief that they may bless the owner or the practitioner with incantations or wisdom deriving from Arabic scripture. While it is certain that juju continues to be popular in Nigerian culture, its pervasiveness within the different subgroups of Nigerian culture remains undetermined. From the cognition of the fact that juju is extensively used and referred in Nigerian culture, it can be inferred that it must also be used by business professionals. Subsequently, a question arises not only in regard to the magnitude of the juju practices practiced by the businessmen but also the motive and intent behind using the same. The incidence of Juju has somehow linked itself with the intention of blood money and spiritual attack. The study is an attempt to identify the motive or intent behind the practice of juju by the businessmen of Nigeria. Word of mouth hints that juju is on the rise in Nigeria because people out 
there want to become rich and escape the trap of poverty. It is being said and well referred that business men in Nigeria follow and practice Juju in order to make money. According to the preachers and the followers, the money keeps on flowing in as long as one continues to perform juju rituals. Some people go for juju for protection from ill luck and competitors and some for fame and prosperity. The worst form of this witchcraft is considered to be the one, where a juju practitioner of follower kills his/her enemy or make their life miserable without physically attacking them. Juju includes both blood money and spiritual attack.

\section{Aims and Objectives}

The aim of the study is to evaluate: Why businessmen in Nigeria may continue to use Juju?

The objectives of the study are as follows:

I. To evaluate if the businessmen in Nigeria follow traditional African beliefs.

II. To examine the possible reasons or intent of the businessmen in using Juju.

III. To identify the expectations of the businessmen in applying Juju.

IV. To assess the extent of usage of Juju in conducting business.

\subsection{Black Magic In Africa}

\section{Literature}

African societies are still under the influence of occult forces, regardless of the educational background of the people in concern, the social class they come from or the religion they follow. In Sub-Saharan Africa, mastering occult forces and rituals is a socio-cultural phenomenon of great importance. Particularly in regions of Nigeria i.e. Western Africa, magic and witchcraft have deep penetrated incidence since generations, regardless of the social strata and the rural urban settings (Kohnert, 1996). The intention of applying black magic may be good or bad. But surmising on "black" magic or witchcraft for realizing one's selfish motifs and even worse, to cause harm to others, is the most taxing as well as the controversial aspect of such belief systems. Most of the peasants, business people, politicians alike, even internationally renowned scientists and leaders of Christian churches have this unanimous take on black magic and witchcraft that it's a huge threat to the African society and since is entwined with the faith and beliefs of the people, it's fractious and intractable to handle the same (Chireau, 2003). In spite of this generative assumption, that education and modernization condenses the prevalence of occult beliefs, the incidence of black magic need not necessarily decrease in the course of modernization (Brain, 1982). In fact, as per the observations of the general people in Africa, the incidence of black magic has rather increased, both in terms of frequency and in terms of effectiveness of the same (Kohnert, 1983; Drucker - Brown, 1993). Belief in black magic and witchcraft might be considered to be as the reaction to the increasing "conflict producing potential" arising out of the processes of social differentiation in regard to the advancement of the market economy and "modernization" of economy and society (Jong, 1987; Kohnert, 1983; Drucker - Brown, 1993).

\subsection{Incidence of Juju}

Juju is a form of black magic practiced majorly in West Africa which is performed and prepared by the native doctors, witch doctors and herbalists. Juju is high on popularity in areas like Nigeria and the people out there consider it as the power of their forefathers and the ancient African gods and goddesses. There are two aspects of Juju: the good juju and the bad juju. The definition and differences between good juju and bad juju depends on the individual or the community or the culture. Usually, in Nigerian culture good juju means good luck and bad juju means bad luck. In other terms, good juju is the juju spell used for healing, giving etc. and bad juju is the magic used to harm or hurt a person or a group of persons for any reason whatsoever (Black Magic.com).

Juju has continuously manifested itself as highly significant and effective a practice among the African tradition and culture. It has been observed in almost all the regions of Nigeria that whenever there is some big event or ceremony, a "rain chaser" is always called and paid accordingly to chase or move out the rain from the area where the ceremony or occasion is being held. These rain makers or rain chasers use juju to perform these tasks. During the rainy season, these rain chasers in Nigeria make a lot of money by using juju to control or chase the direction and magnitude of the rain in a particular area. The juju belief and system might seem primitive but highly effective in most of the cases if not all. Some people bury charms or spells in other people's farms and compounds in order to manipulate or influence in negative or positive way depending on the intentions of the juju carrier or preparer (Msongo, n.d.).

Incidence of Juju has also been seen in the political hierarchy of Africa. In March, 2014, images of a hex (juju) were allegedly retrieved from the residence of the Special Executive Assistant to the President of Sierra Leone, Sylvia Olayinka Blyden. SEA in its defence argument said that desperate competitors were trying to take her off the State House. The presence of "juju arsenal" in Blyden's residence is the proof that even educated and religious people with significant social and political role to play. Juju plays a significant role in 
African politics. It is used for various reasons: to secure positions in government, to get rid of others, to be favoured, to destroy others, to be more powerful and for protection (Africa cradle.com, n.d.).

Incidence of juju is also spotted in the domain of African football. Zimbabwean soccer has been strongly referred with the controversies of juju practices. Soccer fans in the country have by now become pretty used to juju issues and most claim that most of the teams of both Premier Super League and Cup games have their own witchdoctors (Madzivanzira, 2013).

In many parts of Africa, success of a business is attributed to juju instead of hard work. Tales about usage of charms and spells in businesses are quite common among the small scale and informal business such as groceries and market trading. People out there believe that charms can be used to lure customers or bring luck but at the same time they can bring about dangerous results as well (News Day, 2013).

\subsection{Introduction}

\section{Research Methodology}

The study takes as its departure point the belief that business people do indeed use juju, and the purpose of this study is to test this hypothesis. In so doing, the analysis locates the reasons why business people may continue to use juju, as well as what they expect to gain through continuing to use it.

Research Methodology is the organized and sequential way to solve a problem. It is the science of studying how a concerned research should be carried out. The procedure using which the researcher describes his/her work, explains and predicts phenomena (Rajsekar et.al 2006). This chapter describes the broad paradigm underpinning the topic, the chosen research methods, the data collection method and source, the chosen sample and sampling method and the rationale behind all these and the ethical aspects kept in concern while conducting the research.

\subsection{Research Philosophy}

There are primarily three major research paradigms - Positivist, Interpretive and Critical (Dammak). Positivism is a philosophical system of determining the validity of knowledge as it is derived from empirical knowledge. It assumes that social phenomena can be treated like a natural science. Interpretivist philosophy states that all participants involved, including the researcher has their own unique interpretations which need to be captured while conducting a research study. Similar to interpretivist view, the critical researchers identify that research is not value free, but they go a step further by challenging the interpretations and values in order to bring change.

The current study follows a mixed paradigm following both positivism and interpretivist approach. The study considers the factual knowledge gained through observations. The data collected by the researcher is interpreted through objective approach to arrive at quantifiable and observable results. At the same time, the study allowed for the consideration of any special comments or remarks made by the respondent which is otherwise behavioural or qualitative.

\subsection{Research Approach}

There are primarily four major research approaches - Quantitative research, Qualitative research, Pragmatic approach (Mixed approach) and Participatory or Emancipatory approach. The research approach followed in this study is a pragmatic one i.e. it is a mixed approach constituting qualitative and quantitative approach. Being able to use mixed approaches has the advantages of enabling triangulation. It involves data triangulation i.e. the use of a variety of data sources, investigator triangulation which implies the use of several different researches, theory triangulation i.e. the use of multiple perspectives to interpret the results, methodological triangulation i.e. the use of various methods to study a research problem. It is expected that using applying multiple research approaches will provide more expansive perspective of the role of juju among business people.

\subsection{Locale of Study}

In order to conduct this research, it was imperative that we look for a location that adequately represents the business sector of the population. It was therefore determined that the Jimeta-Yola of Adamawa State would be the most appropriate for this analysis. Jimeta-Yola is an ideal site for this research for two main reasons; first, it is the capital city of the Adamawa State and therefore not an extremely marginalized sector of Nigeria; second, Jimeta-Yola represents the primary business venue in Adamawa For this reason, the city has cultivated a reputation as the 'shopping complex', where (primarily) computers and other technological accessories are sold. By focusing on the region of Nigeria that is most concretely aligned with business, the experiment was not only able to draw on a diverse array of business peoples but also held access to a representative population of business culture in Nigeria 


\subsection{Data Collection And Instrumentation}

The most referred form of data collection is done on the basis of the source of the collected data. There are two sources of collecting data - Primary and Secondary sources. Primary data are collected by the investigators themselves for the research study whereas secondary data includes censuses, information collected by the government departments, organizational records and data that was originally collected for other research purposes.

There were three different research methods used: first, a survey was issued; second, focus groups were formulated; and lastly, interviews were conducted. The research instruments varied in their application. For the survey, participants were selected through visiting the business district of Jimeta-Yola and randomly selecting small businesses. Upon selecting the businesses, the survey administrator asked to speak with the manager or owner. Only after receiving the consent of said individual was the questionnaire administered. The administrator also remained with the participant until the questionnaire was completed; in so doing, the instrumentation guaranteed that the survey respondents were in fact the owner or manager.

For the focus groups, discussions were held; the demographic varied substantially from the surveys, as focus group participants were undergraduate students aged 18-27. They were relevant to the current study as they were enrolled in an entrepreneurship business course, preparing a business plan for a business they intend to launch. Five groups were interviewed in total, with sessions lasting between 30 and 45 minutes. The focus group participants offered a perspective that was more inexperienced but no less relevant, as the participants comprise the future generation of business people. Finally, interviews were conducted with students and employees of various small businesses. Sessions consisted of a series of questions that were structured beforehand. Once the data was gleaned from the sampling instruments, it was entered into SPSS. By delivering each of the survey instruments in person, risk was reduced since there exists no ambiguity concerning the identity of the respondents.

\subsection{Sample Size And Sampliing Procedure}

Sampling is a process of technique of choosing a sub-group from the population, for the study. The method of drawing samples from the population can be broadly classified as probabilistic and non-probabilistic sampling methods. The study uses a non-probabilistic random sampling method. A total of 63 participants were taken into consideration for the study, out of which 11 participants formed the focus group, 37 participants were deployed with the qualitative questionnaire and 15 were provided with the quantitative questionnaire.

\section{Results}

Out of 37 participants who were deployed with the qualitative questionnaire, $62.2 \%$ of the respondents were Christian; $35.1 \%$ of them being Muslim and 2.7 being Traditionalist. Out of them, majority of the respondents (43. 2\%) had completed their polytechnic, $21.6 \%$ whose highest achieved education is Senior Secondary; $18.9 \%$ had completed their university studies while $10.8 \%$ of them had studied till Junior Secondary level. Those who had just primary education and the ones with no education formed the share of $2.7 \%$ each. Answers of the $59.5 \%$ of the respondents remained missing and out of the remaining $40.5 \%, 24.3 \%$ considered themselves to be extremely religious while $16.2 \%$ considered themselves somewhat religious. Majority of the respondents i.e. $48.6 \%$ are from the retails, $35.1 \%$ from the service sector, $13.5 \%$ of the respondents from the wholesale sector, while $2.7 \%$ are from other business sectors. $78.4 \%$ of the respondents said that they seek for traditional spiritual guidance from a spiritual leader whereas remaining $21.6 \%$ don't. $32.4 \%$ of the respondents discuss their business with Christian priest/minister, followed by $24.3 \%$ of the respondents who discuss their business with the Muslim Imam while only $2.7 \%$ discuss their business with the leaders of Traditionalist beliefs. It is to be noted that responses of $40.5 \%$ of the respondents are missing. 35.1\% of the respondents use Quran verses as a spiritual measure to save their business against theft, fire, burglary or any such misfortune; $21 . \%$ use the holy water; $10.8 \%$ use charmed brooms while $5.4 . \%$ bury animals and $27 \%$ use some other measures. To prevent evil people from patronizing their business, $24.3 \%$ sprinkle holy water; $8.1 \%$ put on spiritual objects on their body; $5.4 \%$ hang spiritual items. $2.7 \%$ apply spiritual; creams, spray and other cosmetics while $59.5 \%$ perform some other activities to ward off the evil eyes of the people. During the active business hours, $35.1 \%$ wear a charmed ring; $24.3 \%$ wears a cross, $13.5 \%$ wear charmed necklaces or bracelets whereas $27 \%$ opts for some other objects and items. When asked if they know of any spiritual attack in the business domain, 75.7\% denied of experiencing any such incidents and $24.3 \%$ said that they are aware of the incidence of such spiritual attacks. $51.4 \%$ of the respondents said that they renew their traditional spiritual fortification, $13.5 \%$ renew it monthly, and $10.8 \%$ change it daily. $78.4 \%$ of the respondents believe that their religious beliefs do not contradict with their spiritual beliefs, $16.2 \%$ believe it does and $5.4 \%$ are of the view that the contradiction arises sometimes. $54.1 \%$ hold the view that with a potent traditional fortification against theft and burglary, they don't need to employ a body or a security guard; $32.4 \%$ believe that they will need security guard even 
after traditional fortifications. When asked if they put curses on their competitors and rivalries, $59.5 \%$ said they don't, whereas responses of $40.5 \%$ of the respondents are missing.

For the quantitative survey, 15 participants were surveyed. Majority of the sample set believes that people cannot put curse on their business, where equal share of respondents stated that they are not sure of its incidence and they believe in its incidence. When asked whether charms actually work or not, most of the respondents said yes, some of them said not at all. Most of the participants hold the view that charms are used for both good luck and destruction, followed by the share of the respondents who consider it as a destruction tool; very few believed that charms are used only for good luck. Most of the respondents are not sure of the way the curses are bestowed or manifested. Some of the respondents believe that curses are bestowed through verbal speeches and infinitesimally small a number believe it is done through bad prayers. Most of them stated that they do not discuss the spiritual protection with any member of the family. Some broad features came into observation while conducting the focus groups, everyone that was part of the focus group expressed strong beliefs in either Christianity or Islam. Everyone in the focus group believed on the existence of a spiritual realm that is dark, evil and real.

\section{Discussion}

The study of the data collected through survey, interviews and focus groups have demonstrated some key observations which are discussed below:

The most striking feature that was demonstrated in the study is the simultaneous realization of religious belief and traditionalist belief. People, who follow Christianity and Islam, though they are otherwise rigid towards their religious traditions, were also found to follow occult practices. The incidence of black magic prevails regardless of educational background and income or economic conditions. The study demonstrates that the prevalence of Juju is more of socio-psychological phenomena. It's the faith on supernatural powers and the subsequent consequences it generates, which drives the following for black magic among the entrepreneurs. The analysis of the data collected reveals that most of the businessmen, who believe as well use traditional spiritual belief for their business, use some or other form of spiritual fortification in the form of charm bracelets and anklets.

A striking result has surfaced after the data analysis. Though most of the businessmen use some or other form of traditionalist ritual or object to ward off evil eye and competition and to bring good luck and fortune, but $75.7 \%$ of the respondents denied experiencing any spiritual attacks in their business domain. It might imply that they believe in the traditionalist view but are still not oaky with open discussion regarding the same. This definitely develops a scope for further study of the topic.

\section{Conclusion}

The purpose of the study was to identify the magnitude of use of Juju as a black magic among the entrepreneurs of Nigerian region. Most of the businessmen had their own religious beliefs and still majority of them seek guidance from traditionalist spiritual leader. This confirms the role and relevance of traditionalist beliefs that includes occult and black magic beliefs, among the business community of Nigeria. Another noteworthy point is that most of them were educated, which implies that educational background and modernization of thoughts had least impact on the use of black magic. Use of Quranic verses, sprinkling of holy water, wearing spiritual items on the body, hanging of spiritual objects like charms are some of the practices that are practiced by most of the businessmen to ward off evil eyes and to bring luck and fortune to the business.

\section{References}

[1]. Brain, J. L. (1982). Witchcraft and development. African Affairs, 81(324), 371-384.

[2]. Chireau, Y. P. (2003). Black magic: Religion and the African American conjuring tradition. Univ of California Press.

[3]. Dammak, A. Research Paradigms: methodologies and compatible methods.

[4]. De Jong, J. T. (1987). A descent into African Psychiatry. Royal Tropical Institute.

[5]. Does Juju make business thrive. (2013).News Day. Retrieved from https://www.newsday.co.zw/2013/01/26/does-juju-makebusinesses-thrive/Does 'Juju/Black Magic' plays a part in African Politics? www.africacradle.com (n.d.)

[6]. Drucker-Brown, S. (1993). Mamprusi witchcraft, subversion and changing gender relations. Africa, 63(04), 531-549.

[7]. Juju the Dark Side of Voodoo. World Black Magic.Com. Retrieved from http://www.blackmagicworld.com/juju-the-dark-side-ofvoodoo.html

[8]. Kohnert, D. (1983). Indicators of Social and Political Conflict in African Societies: on the articulation of witchcraft among the Nupe, Northern Nigeria. University of Bielefeld, Faculty of Sociology, Sociology of Development Research Centre.

[9]. Kohnert, D. (1996). Magic and witchcraft: Implications for democratization and poverty-alleviating aid in Africa. World Development, 24(8), 1347-1355.

[10]. Madzivanzira, A. (2013). A Closer Look at Juju and Football. The Patriot. Retrieved from http://www.thepatriot.co.zw/old_posts/acloser-look-at-juju-and-football/

[11]. Rajasekar, S., Philominathan, P., \& Chinnathambi, V. (2006). Research methodology. What is Juju? (n.d.) Msongo. Retrieved from http://msongo.blogspot.in/2013/06/what-is-juju.html 